\title{
Inadequate calcium intake is highly prevalent in Korean children and adolescents: the Korea National Health and Nutrition Examination Survey (KNHANES) 2007-2010
}

\author{
Jong Geun Im ${ }^{1}$, Shin Hye Kim ${ }^{1}$, Gyeong-yoon Lee ${ }^{2}$, Hyojee Joung ${ }^{2}$ and Mi-Jung Park ${ }^{1, *}$ \\ ${ }^{1}$ Department of Pediatrics, Sanggye Paik Hospital, Inje University College of Medicine, 761-1 Sanggye-7-dong, \\ Nowon-gu, Seoul 139-707, Republic of Korea: ${ }^{2}$ Public Health Nutrition, School of Public Health, Seoul National \\ University, Seoul, Republic of Korea
}

Submitted 23 June 2013: Final revision received 21 August 2013: Accepted 4 September 2013: First published online 28 0ctober 2013

\begin{abstract}
Objective: The present study aimed to assess the adequacy of Ca intake and major food sources of $\mathrm{Ca}$ in Korean children and adolescents.

Design: A cross-sectional study.

Setting: Data from the Korean National Health and Nutrition Examination Survey (KNHANES) 2007-2010. We analysed the daily Ca intake, major food sources of $\mathrm{Ca}$ and the prevalence of inadequate $\mathrm{Ca}$ intake in the study population. Ca intake was categorized as inadequate when the participant's daily Ca intake was less than the Estimated Average Requirement.

Subject: The study population consisted of 7233 children and adolescents (3973 boys, 3260 girls; aged 1-18 years).

Results: Mean Ca intake was $510.2 \mathrm{mg} / \mathrm{d}$ in boys and $431.7 \mathrm{mg} / \mathrm{d}$ in girls. Overall, $75 \cdot 0 \%$ of adolescents (boys $71 \cdot 6 \%$, girls $79 \cdot 1 \%$ ) had inadequate Ca intake. The prevalence of inadequate $\mathrm{Ca}$ intake increased significantly from toddlers (45-55\%) to adolescents (78-86\%) in both genders. The highest ranked food sources for $\mathrm{Ca}$ were dairy products $(35 \cdot 0 \%)$, followed by vegetables $(17 \cdot 3 \%)$, grains $(11 \cdot 3 \%)$ and seafood $(9 \cdot 9 \%)$. Ca intake from dairy products decreased significantly from $57 \%$ in toddlers to $30 \%$ in adolescents, while Ca intakes from other foods increased with age.

Conclusions: Inadequate $\mathrm{Ca}$ intake is highly prevalent and increased with age in Korean children and adolescents. It should be emphasized to encourage children and adolescents to eat more $\mathrm{Ca}$-rich products to meet their $\mathrm{Ca}$ needs.
\end{abstract}

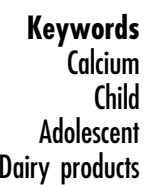

$\mathrm{Ca}$ is the most abundant mineral in the body, accounting for about $1-2 \%$ of body weight and $39 \%$ of total body minerals. Over $99 \%$ of total body $\mathrm{Ca}$ is found in bones and teeth. The remainder is present in blood, extracellular fluid, muscle and other tissues, where it plays a role in mediating vascular contraction, vasodilation, muscle contraction, nerve transmission and glandular secretion ${ }^{(1,2)}$. Since it is involved in many metabolic and cellular functions, $\mathrm{Ca}$ is essential for optimal growth and development ${ }^{(3)}$. Adequate Ca intake during growth is extremely important to reach the optimum peak bone mass, which protects against osteoporosis during adulthood $^{(4)}$.

In respect of the intense growth associated with this period and the need to attain the optimal peak bone mass, Ca deficiency in childhood and adolescent years could lead to a major problem in adulthood. Unfortunately, a lot of children and adolescents worldwide fail to achieve the recommended $\mathrm{Ca}$ intake. Korean children and adolescents are at high risk of low $\mathrm{Ca}$ intake because of their low consumption of dairy products, irregular meals and excessive weight-control practices ${ }^{(5,6)}$. To date, there had been no previous large-scale studies examining the prevalence of low Ca intake in Korean children and adolescents.

In the present study we investigated the amount and major food sources of $\mathrm{Ca}$ intake, and the prevalence of inadequate $\mathrm{Ca}$ intake, in Korean children and adolescents.

\section{Experimental methods}

\section{Study participants}

The data for the present study were obtained from the Korean National Health and Nutrition Examination Survey (KNHANES), 2007-2010. This survey is a community-based cross-sectional survey conducted by the Division of Chronic Disease Surveillance, Korea Centers for Disease Control and Prevention to assess the health and nutritional status of a large representative sample of 
non-institutionalized civilians in South Korea. A stratified, multistage probability sampling design was used for the selection of household units.

A total of 33829 individuals younger than 19 years old participated in the 2007-2010 survey. We excluded respondents who did not attend the $24 \mathrm{~h}$ dietary recall interviews, FFQ or anthropometry investigations. After the exclusion, the sample for the cross-sectional analysis comprised a total of 7233 children and adolescents aged 1-18 years (3973 boys, 3260 girls). The study was conducted according to the guidelines laid down in the Declaration of Helsinki and all procedures involving human subjects were ethically approved by the Institutional Review Board at Inje University College of Medicine. Written informed consent was obtained from all participants or from their parents.

\section{Data collection and study variables}

The KNHANES consists of four survey parts: a health interview survey, a health behaviour survey, a health examination survey and a nutrition survey. Data were collected via household interviews, followed by standardized physical examinations performed by trained medical staff and blood sample collections at a mobile examination centre.

Demographic variables include age, gender, region and household income. Age was categorized according to the criteria used in the Korean Dietary Reference Intakes ${ }^{(7)}$ : 1-2 years, 3-5 years, 6-8 years, 9-11 years, 12-14 years and 15-18 years. Among the sixteen districts of South Korea, eight major cities (Seoul, Gyeonggi, Busan, Daegu, Incheon, Gwangju, Daejeoun and Ulsan) were grouped as urban areas, and the other provinces (Gangwon, Chungbuk, Chungnam, Jeonbuk, Jeonnam, Gyeongbuk, Gyeongnam and Jeju) were grouped as rural areas. Household income was calculated by equivalized gross household income per month per year and grouped into four quartiles.

Obesity, overweight and underweight were categorized according to the age- and sex-specific percentiles for BMI of the Korean national reference standards ${ }^{(8)}$. Underweight, normal weight, overweight and obesity were defined as a BMI percentile of $<5$ th, $\geq 5$ th to $<85$ th, $\geq 85$ th to $<95$ th and $\geq 95$ th, respectively.

Assessments of participants' daily $\mathrm{Ca}$ intake and contributing food sources were done using a $24 \mathrm{~h}$ dietary recall method. Participants recalled the type and amount of all foods they had consumed on the day before the interview, including snacks, beverages and ingredient information for all sauces and condiments. The amount of $\mathrm{Ca}$ in the diet was calculated according to the food composition tables for Koreans ${ }^{(9)}$, a food portion/weight database of foods and dishes ${ }^{(10)}$, a recipe database of eating out and school/industry feeding ${ }^{(11)}$, and a database of processed and fast foods ${ }^{(11)}$. Ca intake was categorized as inadequate when the daily Ca intake of the participant was less than the Estimated Average Requirement (EAR) of the Dietary Reference Intakes for Koreans $2010^{(7)}$ according to gender and age. The EAR for Ca is $390 \mathrm{mg} / \mathrm{d}$, $470 \mathrm{mg} / \mathrm{d}, 580 \mathrm{mg} / \mathrm{d}, 670 \mathrm{mg} / \mathrm{d}, 800 \mathrm{mg} / \mathrm{d}$ and $750 \mathrm{mg} / \mathrm{d}$ for boys aged $1-2$ years, 3-5 years, 6-8 years, 9-11 years, 12-14 years and 15-18 years, respectively; the corresponding values for girls are $390 \mathrm{mg} / \mathrm{d}, 470 \mathrm{mg} / \mathrm{d}, 580 \mathrm{mg} / \mathrm{d}$, $670 \mathrm{mg} / \mathrm{d}, 740 \mathrm{mg} / \mathrm{d}$ and $660 \mathrm{mg} / \mathrm{d}^{(7)}$.

The food group categories were based on the categories of the food database used in KNHANES. Foods were grouped as: dairy products (milk, modified milk powder, formula, breast milk, goat's milk, yoghurt, ice cream, cheese, etc.); vegetables (kimchi, radish leaves, welsh onion, onion, radish, soyabean sprouts, carrot, spinach, etc.); grains (rice, barley, wheat and their products); seafood (boiled and dried anchovy, fish paste, dried and raw shrimp, loach, squid, opossum shrimp, mackerel, etc.); soya (soyabeans, tofu, fried tofu, bean-curd dregs, soya milk, bean flour, etc.); seaweed (sea mustard, laver, sea tangles, seaweed fulvescens, sea lettuce, seaweed fusiforme, etc.); eggs; flavourings (red pepper pastes, soyabean paste, soya sauce, salt, red pepper powder, etc.); fruits; meat \& poultry (chicken, pork, beef, duck, etc.); nuts (sesame, perilla seeds, almonds, peanuts, chestnuts, walnuts, etc.); beverages (fruit and vegetable beverages, juice, carbonated drinks, cocoa beverage, teas, etc.); and others.

Frequency of drinking milk was assessed by the FFQ. The frequency was counted for every one cup $(200 \mathrm{ml})$ of milk consumed by the participants.

\section{Statistical analysis}

We used the KNHANES sampling weight variables, stratum variables and the relevant primary sampling units for analysis that allowed an estimate representative of the entire Korean population samples.

The $\chi^{2}$ test was used to compare the distribution of participants between the categorized variables by PROC SURVEYFREQ. Mean values of daily Ca intake were calculated by SURVEYMEANS, and PROC SURVEYREG was used to test the trend and the difference of means between the categorized variable. A $P$ value $<0 \cdot 05$ was considered significant. All analyses were performed using the statistical software package SAS version $9 \cdot 2$.

\section{Results}

The general characteristics and mean daily $\mathrm{Ca}$ intake of participants are presented in Table 1 . The mean daily Ca intake was higher in boys $(510.2 \mathrm{mg})$ than girls $(431.7 \mathrm{mg}$, $P<0 \cdot 0001)$. Participants who consumed milk more than five times weekly were more prevalent among boys than girls $(56 \cdot 2 \% v .46 \cdot 5 \%, P<0 \cdot 0001)$, whereas those who never consumed milk were more prevalent among girls than boys $(23 \cdot 0 \% v \cdot 13 \cdot 8 \%, P<0 \cdot 0001)$.

The amount of daily $\mathrm{Ca}$ intake was calculated as a percentage of the RDA (\%RDA) for Koreans and is presented 
Table 1 General characteristics of the study participants: 7233 children and adolescents (aged 1-18 years), Korean National Health and Nutrition Examination Survey (KNHANES), 2007-2010

\begin{tabular}{|c|c|c|c|c|c|}
\hline & \multicolumn{2}{|c|}{ Boys ( $n$ 3973) } & \multicolumn{2}{|c|}{ Girls (n 3260) } & \multirow[b]{2}{*}{$P$ value } \\
\hline & $n$ & $\%$ & $n$ & $\%$ & \\
\hline \multicolumn{6}{|l|}{ Age (years) } \\
\hline $1-2$ & 431 & $8 \cdot 1$ & 411 & $8 \cdot 8$ & \multirow[t]{6}{*}{0.48} \\
\hline $3-5$ & 675 & $13 \cdot 1$ & 602 & $12 \cdot 9$ & \\
\hline $6-8$ & 771 & $15 \cdot 3$ & 728 & $16 \cdot 2$ & \\
\hline $9-11$ & 778 & $17 \cdot 9$ & 706 & $18 \cdot 8$ & \\
\hline $12-14$ & 721 & $18 \cdot 4$ & 614 & $17 \cdot 7$ & \\
\hline $15-18$ & 597 & $27 \cdot 2$ & 559 & $25 \cdot 5$ & \\
\hline \multicolumn{6}{|l|}{ BMI status* } \\
\hline Underweight & 198 & $6 \cdot 1$ & 189 & $6 \cdot 1$ & \multirow[t]{4}{*}{$0 \cdot 69$} \\
\hline Normal & 2848 & $74 \cdot 9$ & 2635 & $76 \cdot 4$ & \\
\hline Overweight & 437 & $11 \cdot 8$ & 379 & $11 \cdot 0$ & \\
\hline Obese & 283 & $7 \cdot 2$ & 210 & $6 \cdot 5$ & \\
\hline \multicolumn{6}{|l|}{ Regiont } \\
\hline Urban & 2678 & $71 \cdot 4$ & 2471 & $71 \cdot 1$ & \multirow[t]{2}{*}{$0 \cdot 74$} \\
\hline Rural & 1295 & $28 \cdot 6$ & 1149 & $28 \cdot 9$ & \\
\hline \multicolumn{6}{|l|}{ Household incomeł } \\
\hline Quartile 1 & 392 & $12 \cdot 2$ & 332 & $11 \cdot 1$ & \multirow[t]{4}{*}{0.09} \\
\hline Quartile 2 & 1014 & $26 \cdot 3$ & 954 & $28 \cdot 3$ & \\
\hline Quartile 3 & 1287 & $32 \cdot 0$ & 1258 & $33 \cdot 5$ & \\
\hline Quartile 4 & 1223 & $29 \cdot 4$ & 1014 & $27 \cdot 1$ & \\
\hline \multicolumn{6}{|c|}{ Frequency of milk intake } \\
\hline$<1$ time/week & 169 & $13 \cdot 8$ & 252 & $23 \cdot 0$ & \multirow[t]{3}{*}{$<0.0001$} \\
\hline 1-4 times/week & 348 & $30 \cdot 0$ & 345 & $30 \cdot 6$ & \\
\hline$\geq 5$ times/week & 779 & $56 \cdot 2$ & 563 & $46 \cdot 5$ & \\
\hline Daily Ca intake (mg) & $510 \cdot 2$ & $7 \cdot 1$ & $431 \cdot 7$ & $6 \cdot 8$ & $<0.0001$ \\
\hline
\end{tabular}

Values are presented as number and percentage, except for daily Ca intake (mean and standard error). $P$ values are derived from PROC SURVEY FREQ for categorical variables (age, BMI status, region, household income, and frequency of milk intake) and from the $t$ test for daily $\mathrm{Ca}$ intake.

*Underweight, normal weight, overweight and obese defined as $\mathrm{BMI}<5$ th, $\geq 5$ th to $<85$ th, $\geq 85$ th to $<95$ th and $\geq 95$ th percentile, respectively, of the ageand sex-specific BMI percentiles of the Korean national reference standards ${ }^{(8)}$. tSeoul, Gyeonggi, Busan, Daegu, Incheon, Gwangju, Daejeoun and Ulsan were grouped as urban areas. Gangwon, Chungbuk, Chungnam, Jeonbuk Jeonnam, Gyeongbuk, Gyeongnam and Jeju were grouped as rural areas. ‡Household income was calculated by equivalized gross household income per month in each year and grouped into four quartiles.

by age group in Table 2 . Although the RDA for Ca increases with age (peaking at 12-14 years of age), the participants' Ca intake as \%RDA did not increase accordingly with age. Consequently, daily $\mathrm{Ca}$ intake presented as \%RDA, which was $84 \cdot 2-94 \cdot 1 \%$ in toddlers, decreased dramatically to $49 \cdot 6-60 \cdot 0 \%$ in late adolescence.

Figure 1 demonstrates the prevalence of inadequate $\mathrm{Ca}$ intake by gender and age. The prevalence of inadequate $\mathrm{Ca}$ intake increased gradually from toddlers to adolescents in both boys and girls $(P<0 \cdot 0001)$. The prevalence of inadequate $\mathrm{Ca}$ intake was significantly higher in girls $(79 \cdot 1 \%)$ than in boys $(71 \cdot 6 \%, P<0 \cdot 0001)$.

Table 3 shows major food sources of $\mathrm{Ca}$ of the participants. The highest ranked food sources for Ca were dairy products $(35 \cdot 1 \%)$, followed by vegetables $(17 \cdot 3 \%)$, grains $(11 \cdot 3 \%)$, seafood $(9 \cdot 9 \%)$ and soya $(6 \cdot 4 \%)$ in both boys and girls. The Ca intakes $(\mathrm{mg} / \mathrm{d})$ from most of the food sources were significantly higher in boys than in girls $(P<0 \cdot 05)$, except for seaweed, fruits and beverages $(P>0 \cdot 05)$.

Figure 2 shows the percentage contributions from different food sources to total $\mathrm{Ca}$ intake according to
Table 2 Daily calcium intake $(\mathrm{mg})$ of the study participants: 7233 children and adolescents (3973 boys, 3260 girls; aged 1-18 years), Korean National Health and Nutrition Examination Survey (KNHANES), 2007-2010

\begin{tabular}{|c|c|c|c|c|c|c|}
\hline & \multicolumn{2}{|c|}{ DRI } & \multicolumn{4}{|c|}{ Daily Ca intake } \\
\hline & EAR & $\mathrm{RDA}$ & Mean & SE & $\% \mathrm{EAR}^{\star}$ & $\%$ RDAt \\
\hline \multicolumn{7}{|l|}{ Boys } \\
\hline \multicolumn{7}{|c|}{ Age (years) } \\
\hline $1-2$ & 390 & 500 & $470 \cdot 3$ & $17 \cdot 6$ & $120 \cdot 6$ & $94 \cdot 1$ \\
\hline $3-5$ & 470 & 600 & $449 \cdot 0$ & $11 \cdot 8$ & 95.5 & $74 \cdot 8$ \\
\hline $6-8$ & 580 & 700 & $496 \cdot 7$ & 13.9 & $85 \cdot 6$ & $71 \cdot 0$ \\
\hline $9-11$ & 670 & 800 & $531 \cdot 0$ & $13 \cdot 8$ & $79 \cdot 2$ & $66 \cdot 4$ \\
\hline $12-14$ & 800 & 1000 & $519 \cdot 0$ & $13 \cdot 7$ & 64.9 & $51 \cdot 9$ \\
\hline $15-18$ & 750 & 900 & $539 \cdot 6$ & $18 \cdot 0$ & 71.9 & $60 \cdot 0$ \\
\hline \multicolumn{7}{|l|}{ Girls } \\
\hline \multicolumn{7}{|c|}{ Age (years) } \\
\hline $1-2$ & 390 & 500 & $420 \cdot 9$ & $16 \cdot 6$ & $108 \cdot 0$ & $84 \cdot 2$ \\
\hline $3-\overline{5}$ & 470 & 600 & $405 \cdot 0$ & $14 \cdot 7$ & $86 \cdot 1$ & $67 \cdot \overline{5}$ \\
\hline $6-8$ & 580 & 700 & $436 \cdot 8$ & 11.9 & $75 \cdot 3$ & $62 \cdot 4$ \\
\hline $9-11$ & 670 & 800 & $465 \cdot 2$ & $12 \cdot 2$ & $69 \cdot 4$ & $58 \cdot 1$ \\
\hline $12-14$ & 740 & 900 & $466 \cdot 8$ & $17 \cdot 3$ & $63 \cdot 1$ & $51 \cdot 9$ \\
\hline $15-18$ & 660 & 800 & $396 \cdot 6$ & $13 \cdot 1$ & $59 \cdot 2$ & $49 \cdot 6$ \\
\hline
\end{tabular}

DRI, Dietary Reference Intake; EAR, Estimated Average Requirement. Upper tolerance level of $\mathrm{Ca}$ intake is $2500 \mathrm{mg} / \mathrm{d}$ for all age groups. *The amount of daily $\mathrm{Ca}$ intake calculated as a percentage of the EAR. tThe amount of daily $\mathrm{Ca}$ intake calculated as a percentage of the RDA.

participant age. Ca intake from dairy products decreased by $33 \%$ (from $57 \%$ at age $1-2$ years to $24 \%$ at age 15-18 years, $P<0 \cdot 0001)$, while Ca intakes from vegetables (6.6\% to $22 \cdot 3 \%)$, grains $(7 \cdot 3 \%$ to $13 \cdot 7 \%)$ and seafood $(6 \cdot 9 \%$ to $10 \cdot 4 \%)$ increased significantly with age. Ca intakes from other food sources showed relatively small rises with age, except for $\mathrm{Ca}$ intakes from soya, seaweed and fruits (see online supplementary material).

\section{Discussion}

In the present study we demonstrated that the prevalence of inadequate $\mathrm{Ca}$ intake among Korean children and adolescents is as high as $75.0 \%$ and that it increases markedly with age from toddlers (45-55\%) to adolescents (78-86\%).

Recommended daily $\mathrm{Ca}$ intake differs according to ethnicity and nationality ${ }^{(12)}$, because ethnic differences in fractional $\mathrm{Ca}$ absorption rate and body physique influence Ca needs ${ }^{(13-15)}$. Several dietary factors can influence intestinal $\mathrm{Ca}$ absorption. Adequate vitamin D status is important for $\mathrm{Ca}$ absorption as the synthesis of calbindin, which increases active intestinal $\mathrm{Ca}$ transport, is dependent on calcitriol ${ }^{(13)}$. Habitual low Ca intake increases the fractional $\mathrm{Ca}$ absorption rate by up-regulating active transcellular Ca transport in the duodenum ${ }^{(16)}$. On the other hand, phytate and oxalate in vegetables may decrease the fractional $\mathrm{Ca}$ absorption rate $\mathrm{e}^{(17,18)}$. Several studies have shown that Asian adolescents ${ }^{(13,19)}$ and women $^{(17)}$ have higher fractional Ca absorption compared with Caucasians ${ }^{(20,21)}$, which seems to be related to 


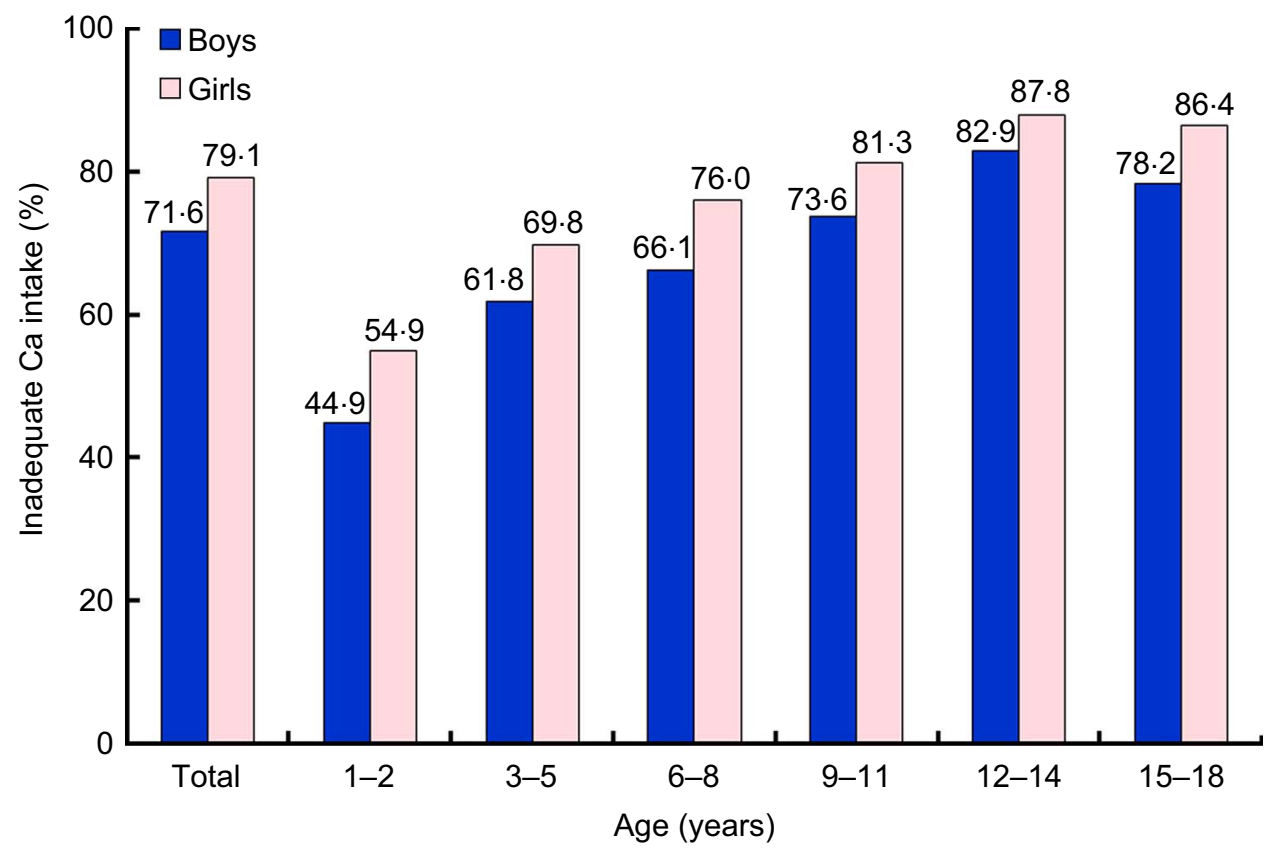

Fig. 1 (colour online) The prevalence of calcium intake less than the Estimated Average Requirement by gender and age among 7233 children and adolescents (3973 boys, 3260 girls; aged 1-18 years), Korean National Health and Nutrition Examination Survey (KNHANES), 2007-2010. $P<0.0001$ for the difference between boys and girls (derived from PROC SURVEYFREQ); $P<0 \cdot 0001$ for the trend by age group in both boys and girls (derived from PROC SURVEYREG)

Table 3 Daily calcium intakes $(\mathrm{mg})$ from major food sources among 7233 children and adolescents (3973 boys, 3260 girls; aged 1-18 years), Korean National Health and Nutrition Examination Survey (KNHANES) 2007-2010

\begin{tabular}{|c|c|c|c|c|c|c|c|c|c|c|}
\hline & \multicolumn{3}{|c|}{ Total } & \multicolumn{3}{|c|}{ Boys } & \multicolumn{3}{|c|}{ Girls } & \multirow[b]{2}{*}{$P$ value } \\
\hline & Mean & SE & $\%$ of total & Mean & SE & $\%$ of total & Mean & SE & $\%$ of total & \\
\hline Dairy products & $211 \cdot 1$ & $4 \cdot 7$ & $35 \cdot 1$ & $228 \cdot 5$ & $5 \cdot 8$ & $35 \cdot 8$ & $191 \cdot 6$ & $6 \cdot 0$ & $34 \cdot 3$ & $<0.0001$ \\
\hline Vegetables & $69 \cdot 0$ & $1 \cdot 2$ & $17 \cdot 3$ & $75 \cdot 5$ & $1 \cdot 6$ & $17 \cdot 4$ & $61 \cdot 6$ & $1 \cdot 4$ & $17 \cdot 2$ & $<0.0001$ \\
\hline Grains & $43 \cdot 5$ & $1 \cdot 0$ & $11 \cdot 3$ & $46 \cdot 6$ & $1 \cdot 6$ & $11 \cdot 2$ & $40 \cdot 0$ & $1 \cdot 2$ & $11 \cdot 4$ & 0.0007 \\
\hline Seafood & $46 \cdot 3$ & $1 \cdot 2$ & $9 \cdot 9$ & $49 \cdot 0$ & $1 \cdot 8$ & $9 \cdot 7$ & $43 \cdot 3$ & $1 \cdot 5$ & $10 \cdot 2$ & 0.01 \\
\hline Soya & $27 \cdot 6$ & 0.9 & $6 \cdot 4$ & $29 \cdot 9$ & $1 \cdot 2$ & $6 \cdot 4$ & $25 \cdot 2$ & $1 \cdot 0$ & $6 \cdot 3$ & 0.0012 \\
\hline Seaweed & $14 \cdot 3$ & 0.5 & $3 \cdot 7$ & $14 \cdot 9$ & 0.6 & 3.5 & $13 \cdot 7$ & 0.6 & 3.9 & $0 \cdot 10$ \\
\hline Eggs & $13 \cdot 1$ & 0.3 & $3 \cdot 7$ & $14 \cdot 5$ & 0.4 & $3 \cdot 7$ & $11 \cdot 5$ & 0.4 & $3 \cdot 7$ & $<0.0001$ \\
\hline Flavourings & $13 \cdot 8$ & 0.3 & $3 \cdot 4$ & $15 \cdot 3$ & 0.5 & $3 \cdot 6$ & $12 \cdot 2$ & 0.4 & $3 \cdot 4$ & $<0.0001$ \\
\hline Fruits & $10 \cdot 7$ & 0.5 & $2 \cdot 9$ & $10 \cdot 2$ & 0.6 & $2 \cdot 5$ & $11 \cdot 2$ & 0.5 & $3 \cdot 3$ & $0 \cdot 18$ \\
\hline Meat \& poultry & $7 \cdot 5$ & 0.2 & $2 \cdot 1$ & $8 \cdot 5$ & 0.3 & $2 \cdot 2$ & $6 \cdot 4$ & 0.2 & $2 \cdot 0$ & $<0.0001$ \\
\hline Nuts & $6 \cdot 1$ & 0.2 & $1 \cdot 5$ & $6 \cdot 5$ & 0.3 & $1 \cdot 4$ & $5 \cdot 7$ & 0.3 & 1.5 & 0.04 \\
\hline Beverages & $4 \cdot 5$ & 0.3 & $1 \cdot 2$ & $4 \cdot 6$ & 0.4 & $1 \cdot 0$ & $4 \cdot 4$ & 0.5 & $1 \cdot 4$ & 0.77 \\
\hline Others & $5 \cdot 8$ & 0.4 & $1 \cdot 4$ & $6 \cdot 4$ & 0.6 & $1 \cdot 4$ & $5 \cdot 1$ & 0.4 & $1 \cdot 4$ & 0.03 \\
\hline
\end{tabular}

Values are presented as mean and standard error and percentage contribution of Ca intake from food source to total daily intake. $P$ values for the gender difference are derived from PROC SURVEYREG.

the low $\mathrm{Ca}$ intake in Asians ${ }^{(2)}$. However, prevalent vitamin D deficiency ${ }^{(22,23)}$ and the vegetable-rich diet among Asian populations ${ }^{(17,18)}$ may interfere with $\mathrm{Ca}$ absorption, resulting in poor mineral accretion and osteoporosis in later life. The 2011 report of the Institute of Medicine stated that the recommended $\mathrm{Ca}$ intake ranges from $700 \mathrm{mg} / \mathrm{d}$ (1-3 years) to $1300 \mathrm{mg} / \mathrm{d}$ (9-18 years) and the EAR from $500 \mathrm{mg} / \mathrm{d}$ (1-3 years) to $1100 \mathrm{mg} / \mathrm{d}$ (9-18 years) for American and Canadian children and adolescents ${ }^{(24)}$. On the other hand, the RDA (500-1000 mg/d) and EAR $(390-800 \mathrm{mg} / \mathrm{d})$ of $\mathrm{Ca}$ for Korean children ${ }^{(7)}$ are about 100-200 mg/d lower than those for American children.
A report from the US National Health and Nutrition Examination Survey 2005-2006 demonstrated that the mean $\mathrm{Ca}$ intake in US children and adolescents (aged 1-18 years) was $950-1250 \mathrm{mg} / \mathrm{d}$, and the 5 th percentile value of Ca intake was $400-600 \mathrm{mg} / \mathrm{d}^{(25)}$. By contrast, we found that the mean $\mathrm{Ca}$ intake in Korean children and adolescents was $400-540 \mathrm{mg} / \mathrm{d}$, which corresponds to the 5 th percentile of $\mathrm{Ca}$ intake in US children. In spite of the much lower EAR of $\mathrm{Ca}$ for Koreans, $50 \%$ of toddlers and more than $80 \%$ of adolescents did not meet the EAR. UK children and adolescents ${ }^{(26)}$, whose RDA for $\mathrm{Ca}$ intake is close to that of Koreans, also have 


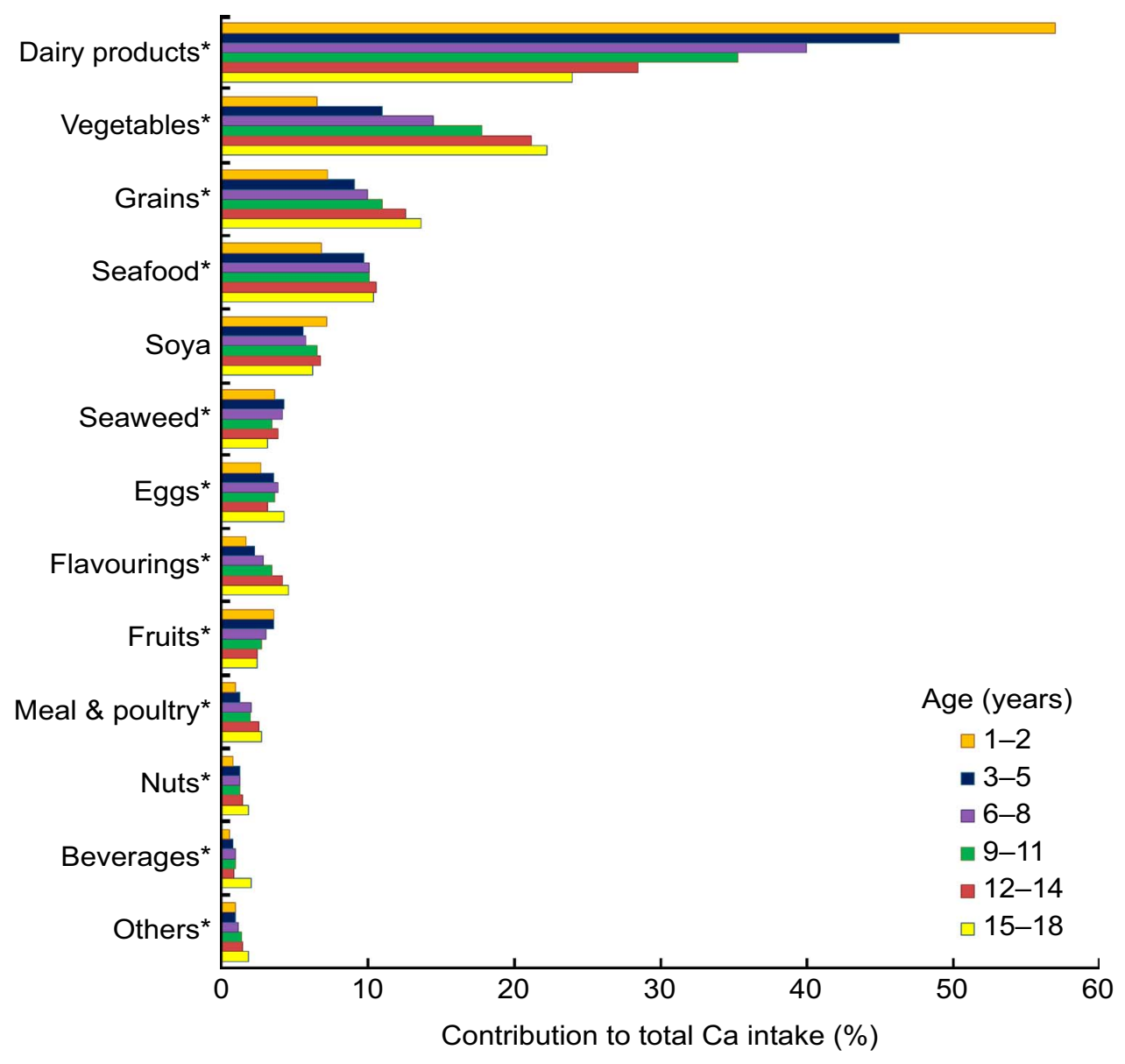

Fig. 2 (colour online) Contributions of food sources to total calcium intake by age among 7233 children and adolescents (3973 boys, 3260 girls; aged 1-18 years), Korean National Health and Nutrition Examination Survey (KNHANES), 2007-2010. * $P<0 \cdot 05$ for the trend by age group (derived from PROC SURVEYREG)

higher Ca intake $(650-860 \mathrm{mg} / \mathrm{d})$ than Korean children and adolescents.

Although little is known about the Ca intake in Korean children, a few studies from other Asian countries have shown lower $\mathrm{Ca}$ intake of children and adolescents as compared with Western counterparts. It has been reported that deficient $\mathrm{Ca}$ intake is highly prevalent among Chinese adolescents ${ }^{(27)}$ and primary-school children in Taiwan $^{(28)}$ and Vietnam ${ }^{(29)}$. Most of all, relatively low dairy consumption can explain the deficient $\mathrm{Ca}$ intake in Asian children. Dairy products are one of the most Ca-rich foods with high bioavailability, contributing up to $70 \%$ of total daily $\mathrm{Ca}$ intake in Western countries ${ }^{(30)}$. In the present study, dairy products were the main food source for Ca in Korean children and adolescents; however, its contribution was only $35 \%$ of daily Ca intake. The Asian diet is traditionally non milk-based, and major food sources for $\mathrm{Ca}$ are vegetables with dark-green leaves, soya and small fish eaten with bones, which have relatively lower Ca contents than dairy products ${ }^{(31)}$. The high prevalence of lactose intolerance (80-90\%) among Asians and the limited supply of lactose-free milk in Asian markets also may limit the Ca intake ${ }^{(32)}$. Like many other Asians, Koreans' milk consumption is lower than that of the Western population. The frequency of milk consumption in Koreans is $2 \cdot 8$ times weekly, with $80 \%$ of individuals drinking less than one serving daily ${ }^{(33)}$. The recommended milk intake for children and adolescents ranges from 300 to $750 \mathrm{ml} / \mathrm{d}$ in several countries $^{(34-36)}$, and about two cups ( $400 \mathrm{ml}$ ) of milk daily are suggested by the Korean Nutrition Society ${ }^{(7)}$. However, only $50 \%$ of the participants drink milk more than five times weekly in the present study.

Consistent with other studies ${ }^{(37-39)}$, the daily Ca intake of boys was about $100 \mathrm{mg}$ higher than that of girls in the present study. The prevalence of inadequate $\mathrm{Ca}$ intake was higher in girls than in boys for all age groups. Higher milk consumption and larger portion size in the diet of boys compared with girls could explain this discrepancy.

Ca needs in children are considerably elevated with age as a result of the intensive bone and muscular developments. However, daily Ca intakes remained constant at 400-540 mg in the present study (age 1-18 years), and consequently daily $\mathrm{Ca}$ intake as \%RDA decreased from $84-94 \%$ (1-2 years) to 50-60\% (15-18 years) with 
age. The decreasing trend of $\mathrm{Ca}$ intake with age seems to be associated with the decreasing trend of dairy consumption. Dairy consumption, which provides $60 \%$ of daily $\mathrm{Ca}$ in toddlers, decreases in teens down to $30 \%$. Although the contributions from vegetables and grains increase with age, $\mathrm{Ca}$ intake from all food sources excluding dairy products was as low as $260 \mathrm{mg} / \mathrm{d}$. There are several food sources with high Ca content (mg per standard serving) in traditional Korean diets, such as tofu $(75.6 \mathrm{mg} / 60 \mathrm{~g})$, dried icefish $(98.2 \mathrm{mg} / 10 \mathrm{~g})$, dried anchovy $(64.5 \mathrm{mg} / 5 \mathrm{~g})$, radish leaves $(149 \mathrm{mg} / 60 \mathrm{~g})$ and mugwort $(103.5 \mathrm{mg} / 45 \mathrm{~g})$. Especially tofu ${ }^{(40)}$, small softboned fish ${ }^{(41)}$ and Ca-fortified soya milk ${ }^{(42)}$ have been proven to be good sources of $\mathrm{Ca}$, as their $\mathrm{Ca}$ absorption is comparable to that from cow's milk. Dark-green leafy vegetables and soyabeans are also important $\mathrm{Ca}$ sources in Korean $\operatorname{diets}^{(43)}$, although their Ca bioavailability is lower than that of dairy products ${ }^{(40)}$. Some vegetables with high $\mathrm{Ca}$ and low oxalate/phytate content, such as kale and broccoli, can contribute to the Ca needs of nonmilk drinkers ${ }^{(17,40)}$. Since $50 \%$ of total adult skeletal mass is achieved during adolescence, a positive $\mathrm{Ca}$ balance in this period is mandatory to achieve the maximum peak bone mass ${ }^{(44)}$. Children and adolescents whose Ca intake is below $500 \mathrm{mg} / \mathrm{d}$ need more than $50 \%$ of intestinal Ca absorption rate to maintain Ca balance ${ }^{(12)}$. Considering the high prevalence (70\%) of vitamin D deficiency in Korean adolescents ${ }^{(23)}$, adequate $\mathrm{Ca}$ intake is important to achieve optimal bone accretion and growth. We suggest that interventions designed to promote improvements in $\mathrm{Ca}$ intake should emphasize strategies that encourage consumption of milk and other Ca-rich foods (tofu, small fish eaten with bones, dark-green leafy vegetables) and of also Ca- and vitamin D-fortified products (soya milk, cereals). As parental dietary habits associated with $\mathrm{Ca}$ intake, such as drinking milk themselves and having Ca-rich foods in their diet, can influence children's Ca intake, strategies should focus especially on parents. Also, further research using Ca bioavailability tests is needed to identify Korean ingredients as good sources for $\mathrm{Ca}$.

There were some limitations in our study. First, the study was cross-sectional and therefore causality cannot be inferred. Second, the one day $24 \mathrm{~h}$ recall method used in the present study has some limitations in assessing longterm Ca intake. Last, Ca intake from supplements was not analysed in the KNHANES, so we could not assess the effect of $\mathrm{Ca}$ supplements. Nevertheless, to our knowledge, the present study is the first one that demonstrates the prevalence of low $\mathrm{Ca}$ intake and food sources for $\mathrm{Ca}$ in Korean children and adolescents by using the most recent national data.

\section{Conclusion}

Inadequate $\mathrm{Ca}$ intake was highly prevalent among healthy Korean children and adolescents. Due to the decrease of milk consumption with age, deficient $\mathrm{Ca}$ intake tended to be worse especially in adolescence. We suggest that additional efforts are needed to educate adolescents and their parents on the importance of $\mathrm{Ca}$ intake for healthy bones and to encourage the consumption of Ca-rich foods.

\section{Acknowledgements}

Sources of funding: This research was supported by the 2011 Inje University research grant. Inje University had no role in the design, analysis or writing of this article. Conflicts of interest: The authors declare that there are no conflicts of interests. Authors' contributions: J.G.I., S.H.K. and M.-J.P. were responsible for the conception and design of the study. G.L. performed the data analysis and all authors had a role in interpretation of the data. J.G.I., S.H.K. and M.-J.P. drafted the manuscript and H.J. revised and commented on the draft. All authors read and approved the final manuscript. Acknowledgements: The authors thank the Korea Centers for Disease Control and Prevention for providing the data.

\section{Supplementary material}

To view supplementary material for this article, please visit http://dx.doi.org/10.1017/S1368980013002826

\section{References}

1. Cashman KD (2002) Calcium intake, calcium bioavailability and bone health. Br J Nutr 87, Suppl. 2, S169-S177.

2. Institute of Medicine (1997) Dietary Reference Intakes for Calcium, Phosphorus, Magnesium, Vitamin D, and Fluoride. Washington, DC: National Academies Press.

3. Mesías M, Seiquer I \& Navarro MP (2011) Calcium nutrition in adolescence. Crit Rev Food Sci Nutr 51, 195-209.

4. Stang J \& Story M (2005) Nutrition needs of adolescent. In Guidelines for Adolescent Nutrition Services, pp. 21-34 [J Stang and M Story, editors]. Minneapolis, MN: Center for Leadership Education and Training in Maternal and Child Nutrition, Division of Epidemiology and Community Health, School of Public Health, University of Minnesota.

5. Lee K (2012) Weight-related behaviors among non-overweight adolescents: results from the Korean national survey from 2005 to 2007. Asia Pac J Clin Nutr 21, 215-219.

6. Ha Y, Choi E, Seo Y et al. (2013) Relationships among subjective social status, weight perception, weight control behaviors, and weight status in adolescents: findings from the 2009 Korea Youth Risk Behaviors Web-Based Survey. J Sch Health 83, 273-280.

7. Yoon JS, Lee SY, Lim HJ et al. (2010) Calcium. In Dietary Reference Intakes for Koreans, 2nd ed. pp. 337-352 [YS Choi and HK Moon, editors]. Seoul: Korean Nutrition Society.

8. Moon JS, Lee SY, Nam CM et al. (2008) 2007 Korean National Growth Charts: review of developmental process and an outlook. Korean J Pediatr 51, 1-25.

9. National Rural Nutrition Institute, Government of the Republic of Korea (2012) Rural Nutrition Institute \& Rural Development Administration Food Composition Tables. Seoul: National Rural Nutrition Institute. 
10. Korea Health Industry Development Institute (2007) Development of Food and Nutrient Database: Food Portion/Weight Database. Seoul: Ministry of Health and Welfare \& Korea Health Industry Development Institute.

11. Ministry of Health and Welfare, Government of the Republic of Korea (2000) Development of Food and Nutrient Database. Seoul: Ministry of Health and Welfare.

12. Wang Y \& Li S (2008) Worldwide trends in dairy production and consumption and calcium intake: is promoting consumption of dairy products a sustainable solution for inadequate calcium intake? Food Nutr Bull 29, 172-185.

13. Lee WTK, Cheng JCY, Jiang J et al. (2002) Calcium absorption measured by stable calcium isotopes $\left({ }^{42} \mathrm{Ca} \&\right.$ ${ }^{44} \mathrm{Ca}$ ) among northern Chinese adolescents with low vitamin D status. J Orthop Surg 10, 61-66.

14. Abrams SA, O'Brien KO, Liang LK et al. (1995) Differences in calcium absorption and kinetics between black and white girls aged 5-16 years. J Bone Miner Res 10, 829-833.

15. Braun M, Palacios C, Wigertz K et al. (2007) Racial differences in skeletal calcium retention in adolescent girls with varied controlled calcium intakes. Am J Clin Nutr 85, 1657-1663.

16. Bronner F \& Pansu D (1999) Nutritional aspects of calcium absorption. J Nutr 129, 9-12.

17. Charoenkiatkul S, Kriengsinyos W, Tuntipopipat S et al. (2008) Calcium absorption from commonly consumed vegetables in healthy Thai women. J Food Sci 73, H218-H221.

18. Yeudall F, Gibson RS, Cullinan TR et al. (2005) Efficacy of a community-based dietary intervention to enhance micronutrient adequacy of high-phytate maize-based diets of rural Malawian children. Public Health Nutr 8, 826-836.

19. Lee WT, Leung SS, Fairweather-Tait SJ et al. (1994) True fractional calcium absorption in Chinese children measured with stable isotopes $\left({ }^{42} \mathrm{Ca}\right.$ and $\left.{ }^{44} \mathrm{Ca}\right)$. Br J Nutr 72, 883-897.

20. Heaney RP, Weaver CM \& Fitzsimmons ML (1990) Influence of calcium load on absorption fraction. $J$ Bone Miner Res $\mathbf{5}$, $1135-1138$.

21. Abrams SA \& Stuff JE (1994) Calcium metabolism in girls: current dietary intakes lead to low rates of calcium absorption and retention during puberty. Am J Clin Nutr 60, 739-743.

22. Nakamura K, Nashimoto M, Matsuyama $S$ et al. (2001) Low serum concentrations of 25-hydroxyvitamin D in young adult Japanese women: a cross sectional study. Nutrition 17, 921-925.

23. Kim SH, Oh MK, Namgung R et al. (2012) Prevalence of 25-hydroxyvitamin D deficiency in Korean adolescents: association with age, season and parental vitamin D status. Public Health Nutr (Epublication ahead of print version).

24. Ross AC, Manson JE, Abrams SA et al. (2011) The 2011 report on dietary reference intakes for calcium and vitamin D from the Institute of Medicine: what clinicians need to know. J Clin Endocrinol Metab 96, 53-58.

25. US Department of Agriculture (2012). What We Eat In America. http://www.ars.usda.gov/Services/docs.htm? docid $=18349$ (accessed May 2013).

26. Whitton C, Nicholson SK, Roberts C et al. (2011) National Diet and Nutrition Survey: UK food consumption and nutrient intakes from the first year of the rolling programme and comparisons with previous surveys. Br J Nutr 106, 1899-1914

27. He Y, Zhai F, Wang Z et al. (2007) Status of dietary calcium intake of Chinese residents. Wei Sheng Yan Jiu 36, 600-602.
28. Wu SJ, Pan WH, Yeh NH et al. (2007) Dietary nutrient intake and major food sources: the Nutrition and Health Survey of Taiwan Elementary School Children 2001-2002. Asia Pac J Clin Nutr 16, Suppl. 2, 518-533.

29. Ta TM, Nguyen KH, Kawakami M et al. (2003) Micronutrient status of primary school girls in rural and urban areas of South Vietnam. Asia Pac J Clin Nutr 12, 178-185.

30. Nicklas TA (2003) Calcium intake trends and health consequences from childhood through adulthood. $J \mathrm{Am}$ Coll Nutr 22, 340-356.

31. Lee WTK \& Jiang Ji (2008) Calcium requirements for Asian children and adolescents. Asia Pac J Clin Nutr 17, Suppl. 1, 33-36.

32. Vesa TH, Marteau P \& Korpela R (2000) Lactose intolerance. J Am Coll Nutr 19, Suppl. 2, 165S-175S.

33. Korea Institute for Health and Social Affairs (2011) The Third Korea National Health and Nutrition Examination Survey (KNHANES III), 2011 - Summary. Ministry of Health and Welfare. http://knhanes.cdc.go.kr (accessed May 2013).

34. US Department of Agriculture \& US Department of Health and Human Services (2010) Dietary Guidelines for Americans, 2010, 7th ed, Washington, DC: US Government Printing Office; available at http://www.dietaryguidelines. gov

35. National Health and Medical Research Council (2006) Nutrient reference values for Australia and New Zealand including recommended dietary intakes. http://www. nhmrc.gov.au/_files_nhmrc/file/publications/synopses/n35. pdf (accessed May 2013)

36. Health Promotion Board, Singapore Government (2013) A Healthy Food Foundation - for Kids and Teens. http://www. hpb.gov.sg/foodforhealth/article.aspx?id=6086\&lifestage $=$ Children (accessed May 2013).

37. Rajeshwari R, Nicklas TA, Yang SJ et al. (2004) Longitudinal changes in intake and food sources of calcium from childhood to young adulthood: the Bogalusa Heart Study. J Am Coll Nutr 23, 341-350.

38. Larson NI, Neumark-Sztainer D, Harnack L et al. (2009) Calcium and dairy intake: longitudinal trends during the transition to young adulthood and correlates of calcium intake. J Nutr Educ Behav 41, 254-260.

39. Sanwalka NJ, Khadilkar AV, Mughal MZ et al. (2010) A study of calcium intake and sources of calcium in adolescent boys and girls from two socioeconomic strata, in Pune, India. Asia Pac J Clin Nutr 19, 324-329.

40. Weaver CM \& Plawecki KL (1994) Dietary calcium: adequacy of a vegetarian diet. Am J Clin Nutr 59, Suppl. 5, 1238S-1241S.

41. Hansen M, Thilsted SH, Sandström B et al. (1998) Calcium absorption from small soft-boned fish. J Trace Elem Med Biol 12, 148-154.

42. Tang AL, Walker KZ, Wilcox G et al. (2010) Calcium absorption in Australian osteopenic post-menopausal women: an acute comparative study of fortified soymilk to cows' milk. Asia Pac J Clin Nutr 19, 243-249.

43. Park HM, Heo J \& Park Y (2011) Calcium from plant sources is beneficial to lowering the risk of osteoporosis in postmenopausal Korean women. Nutr Res 31, 27-32.

44. Loud KJ \& Gordon CM (2006) Adolescent bone health. Arch Pediatr Adolesc Med 160, 1026-1032. 